\title{
Casein Kinase 1 Suppresses Activation of REST in Insulted Hippocampal Neurons and Halts Ischemia-Induced Neuronal Death
}

\author{
Naoki Kaneko, ${ }^{\star}$ Jee-Yeon Hwang, ${ }^{\star}$ Michael Gertner, Fabrizio Pontarelli, and R. Suzanne Zukin \\ Dominick P. Purpura Department of Neuroscience, Albert Einstein College of Medicine, New York, New York 10461
}

Repressor Element-1 (RE1) Silencing Transcription Factor/Neuron-Restrictive Silencer Factor (REST/NRSF) is a gene-silencing factor that is widely expressed during embryogenesis and plays a strategic role in neuronal differentiation. Recent studies indicate that REST can be activated in differentiated neurons during a critical window of time in postnatal development and in adult neurons in response to neuronal insults such as seizures and ischemia. However, the mechanism by which REST is regulated in neurons is as yet unknown. Here, we show that REST is controlled at the level of protein stability via $\beta$-TrCP-dependent, ubiquitin-based proteasomal degradation in differentiated neurons under physiological conditions and identify Casein Kinase 1 (CK1) as an upstream effector that bidirectionally regulates REST cellular abundance. CK1 associates with and phosphorylates REST at two neighboring, but distinct, motifs within the C terminus of REST critical for binding of $\beta$-TrCP and targeting of REST for proteasomal degradation. We further show that global ischemia in rats in vivo triggers a decrease in CK1 and an increase in REST in selectively vulnerable hippocampal CA1 neurons. Administration of the CK1 activator pyrvinium pamoate by in vivo injection immediately after ischemia restores CK1 activity, suppresses REST expression, and rescues neurons destined to die. Our results identify a novel and previously unappreciated role for CK1 as a brake on REST stability and abundance in adult neurons and reveal that loss of CK1 is causally related to ischemia-induced neuronal death. These findings point to $\mathrm{CK} 1$ as a potential therapeutic target for the amelioration of hippocampal injury and cognitive deficits associated with global ischemia.

\section{Introduction}

Repressor Element-1 (RE1) Silencing Transcription Factor/ Neuron-Restrictive Silencer Factor (REST/NRSF) is a genesilencing transcription factor that is widely expressed during embryogenesis and is critical for elaboration of the neuronal phenotype. REST actively represses a large array of coding and noncoding neuron-specific genes important to synaptic plasticity and structural remodeling, including synaptic vesicle proteins, channels, receptors, and microRNAs that regulate networks of nonneuronal genes (Ballas and Mandel, 2005; Ooi and Wood, 2007; Qureshi and Mehler, 2009; Hwang et al., 2013). During the final stages of neuronal differentiation, downregulation of REST is critical to acquisition of the neuronal phenotype (Ballas and Mandel, 2005). In mature neurons, REST is quiescent, but can be

Received Sept. 19, 2013; revised Feb. 26, 2014; accepted March 23, 2014.

Author contributions: N.K., J.-Y.H., and R.S.Z. designed research; N.K., J.-Y.H., M.G., and F.P. performed research;

N.K., J.-Y.H., and R.S.Z. analyzed data; N.K., J.-Y.H., M.G., and R.S.Z. wrote the paper.

${ }^{*}$ N.K. and J-Y.H. contributed equally to this work.

This work was supported by the National Institutes of Health (Grant NS46742 to R.S.Z.), the McKnight Foundation (Brain Disorders Award to R.S.Z.), and the F.M. Kirby Foundation. R.S.Z. is the F.M. Kirby Professor in Neural Repair and Protection. We thank Brenda Court-Vazquez and Adrianna Latuzsek-Barrantes for technical assistance; all members of the Zukin laboratory for helpful comments; and Hiroyuki Inuzuka and Michele Pagano for providing CK1 and REST constructs, respectively.

The authors declare no competing financial interests.

Correspondence should be addressed to: Dr. R. SuzanneZukin, Dominick P. Purpura Department of Neuroscience, Rose F. Kennedy Center, Room 610, Albert Einstein College of Medicine, 1300 Morris Park Avenue, New York, NY 10461. E-mail: suzanne.zukin@einstein.yu.edu.

DOI:10.1523/JNEUROSCI.4045-13.2014

Copyright $\odot 2014$ the authors $\quad 0270-6474 / 14 / 346030-10 \$ 15.00 / 0$ reactivated in hippocampal neurons during normal postnatal development, driving the switch from immature to mature NMDA receptors (NMDARs; Rodenas-Ruano et al., 2012) and in selectively vulnerable hippocampal neurons by ischemic insults (Calderone et al., 2003; Formisano et al., 2007; Noh et al., 2012) and seizures (Palm et al., 1998; Huang et al., 2002). In Huntington's disease, REST aberrantly accumulates in the nucleus of medium aspiny striatal neurons (Zuccato et al., 2003).

In cancer cells and pluripotent stem cells, REST is bidirectionally regulated by $\beta$-TrCP-dependent, ubiquitin-based proteasomal degradation (Guardavaccaro et al., 2008; Westbrook et al., 2008; Singh et al., 2011) and HAUSP-dependent deubiquitination (Huang et al., 2011). In the transition from neural progenitors to neurons, REST is downregulated by transcriptional repression and protein degradation (Ballas et al., 2005). REST harbors two neighboring, but distinct, noncanonical degron motifs in its C terminus (Weissman, 2008). Phosphorylation of serine residues within these motifs enables binding by the E3 ubiquitin ligase $\beta$-TrCP, priming REST for ubiquitin-based proteosomal degradation. Whereas the mechanism by which REST expression is regulated in stem cells and neural progenitors is established, the upstream kinase that phosphorylates REST is as yet unknown.

Casein Kinase 1 (CK1) is a serine/threonine kinase that is evolutionary conserved and plays a pivotal role in membrane transport, cell division, DNA repair, and activation of transcription factors such as $\beta$-catenin and p53 (Polakis, 2002; Price, 2006). CK1 has seven isoforms, each encoded by a unique gene. 
CK1 $\delta$ and $\mathrm{CK} 1 \varepsilon$ are abundantly expressed in hippocampus, where they regulate NMDAR function (Chergui et al., 2005) and are activated by group I mGluRs (Liu et al., 2002). A prevailing view is that CK1 family members are constitutively active.

The present study was undertaken to characterize the mechanism by which REST is activated in adult neurons under physiological conditions and in response to neuronal insults. We identify CK1 as the upstream kinase that associates with and phosphorylates REST at sites within its degron motifs and targets REST for $\beta$-TrCP-dependent, ubiquitin-based proteasomal degradation. Global ischemia in vivo triggers a decrease in CK1 and $\beta$-TrCP, thereby increasing REST in CA1 neurons. A single, acute injection of the CK1 activator pyrvinium after the ischemic episode affords robust neuroprotection in a clinically relevant model of global ischemia. Our results point to CK1 as a brake on REST expression in differentiated neurons under physiological conditions and reveal that loss of $\mathrm{CK} 1$ in response to ischemic insults is causally related to neuronal death.

\section{Materials and Methods}

Animals. Age-matched adult male Sprague Dawley rats (Charles River Laboratories) weighing 150-200 g were maintained in a temperatureand light-controlled environment with a 12:12 h light/dark cycle and were treated in accordance with the principles and procedures of the National Institutes of Health Guidelines for the Care and Use of Laboratory Animals. Protocols were approved by the Institutional Animal Care and Use Committee of the Albert Einstein College of Medicine.

Cell culture, drug treatment, and transfection. HeLa and N2A cells were plated on culture dishes or plates maintained in DMEM supplemented with $10 \%$ FBS in an incubator with an atmosphere of $10 \%$ $\mathrm{CO}_{2}$ at $37^{\circ} \mathrm{C}$. Cells were grown to $70-80 \%$ confluency for drug treatment or transfection. Cells were transfected with various constructs using Lipofectamine 2000 (Invitrogen). To monitor the impact of CK1 and other kinases on REST, cells were treated with the CK1 activator pyrvinium pamoate (Sigma), the CK1 inhibitor D4476 (Tocris Bioscience), the PKA inhibitor H89 (Sigma), or the PI3 kinase inhibitor LY294002 (Sigma) at the indicated concentrations. To monitor the impact of CK1 on the rate of protein degradation, HeLa cells were treated with pyrvinium $(10 \mu \mathrm{M})$ or D4476 (10 $\mu \mathrm{M})$ for $2 \mathrm{~h}$ before application of the protein synthesis inhibitor cycloheximide $(100 \mu \mathrm{g} /$ $\mathrm{ml}$; Calbiochem). At the indicated times, whole-cell lysates were prepared and subjected to Western blot analysis. Immunoblots were probed with antibodies to REST or $\beta$-actin antibody.

Primary cultures of hippocampal neurons and oxygen-glucose deprivation. Primary cultures of hippocampal neurons were prepared from embryonic day 18 (E18) rats as described previously (Noh et al., 2012). Cultures were maintained $14 \mathrm{~d}$ in vitro before experiments. To monitor the impact of CK1 on REST, neurons were treated with pyrvinium (10 $\mu \mathrm{M})$, D4476 $(10 \mu \mathrm{M})$, or clasto-lactacystin $\beta$-lactone (lactacystin, $2.5 \mu \mathrm{M}$; Calbiochem) for $24 \mathrm{~h}$. To induce oxygen-glucose deprivation (OGD), primary cultures of hippocampal neurons were exposed to serum-free, glucose-free medium saturated with $95 \% \mathrm{~N}_{2} / 5 \% \mathrm{CO}_{2}\left(30 \mathrm{~min}\right.$ at $\left.37^{\circ} \mathrm{C}\right)$ in an airtight, anoxic chamber (Billups-Rothenberg). Cultures were returned to oxygenated, glucose-containing medium under normoxic conditions for $24 \mathrm{~h}$ and were used for Western blotting analysis or immunoprecipitation.

Global ischemia. Animals were subjected to transient global ischemia by the four-vessel occlusion paradigm described previously (Noh et al., 2012; Ofengeim et al., 2012). For sham surgery, animals were subjected to the same anesthesia and surgical conditions, except that the carotid arteries were not occluded. Body temperature was maintained at $37.5 \pm$ $0.5^{\circ} \mathrm{C}$ by external warming until recovery from anesthesia. Animals that failed to show complete loss of the righting reflex and dilation of the pupils 2 min after occlusion was initiated and the rare animals that exhibited obvious behavioral manifestations (abnormal vocalization when handled, generalized convulsions, loss of $>20 \%$ body weight by 3-7 d, or hypoactivity) were excluded from the study.
Drug injections in vivo. Lactacystin ( $1 \mu \mathrm{g} / \mu \mathrm{l}$, dissolved in DMSO) or DMSO was administered to rats by stereotaxic injection directly into the right hippocampal CA1 ( $3.0 \mathrm{~mm}$ posterior and $2.0 \mathrm{~mm}$ lateral to bregma, $4.0 \mathrm{~mm}$ below the skull surface) using a 28 gauge needle and a Hamilton syringe at a flow rate of $0.5 \mu \mathrm{l} / \mathrm{min}(\operatorname{total} 2 \mu \mathrm{l})$. The needle was left in place for an additional $5 \mathrm{~min}$ and then gently withdrawn. The CA1 subfield was rapidly microdissected $24 \mathrm{~h}$ after injection and used for Western blot analysis. Pyrvinium (1 mM, dissolved in DMSO) or DMSO was administered to animals immediately after ischemia or sham surgery by intracerebroventricular injection. For intracerebroventricular injection, a 28 gauge needle attached to a Hamilton syringe was stereotaxically lowered into the right lateral ventricle at a flow rate of $1 \mu \mathrm{l} / \mathrm{min}$ (total $5 \mu \mathrm{l}$ ) to a position defined by the following coordinates relative to bregma: 0.92 $\mathrm{mm}$ posterior, $1.2 \mathrm{~mm}$ lateral, $3.6 \mathrm{~mm}$ below the skull surface.

Plasmids. Myc-CK1 and shCK1 constructs were kind gifts from Dr. Hiroyuki Inuzuka (Department of Pathology, Beth Israel Deaconess Medical Center, Harvard Medical School, Boston, MA). HA-REST construct was obtained Dr. Michele Pagano (NYU Cancer Institute Department of Pathology, New York University School of Medicine And Howard Hughes Medical Institute, New York, NY). HA-REST mutants were generated using the PfuTurboDNA Polymerase (Stratagene) according to the manufacturer's instructions.

shRNAs and lentiviral vectors. CK $1 \varepsilon$ shRNA, $\beta$-TrCP $1 / 2$, and nontargeting (NT) shRNA, a silencer-resistant sequence that does not target any known eukaryotic gene sequence, were engineered in the pcDNA 6.2GW/EmGFP shRNA expression vector (Invitrogen) using the following: CK1 $\varepsilon$ shRNA ( $5^{\prime}$-TAC ATG AGC ACA TAG CCC AGG-3'), $\beta$-TrCP1 $\left(5^{\prime}\right.$-AAC TCT TCC AGA ATG CTC CAC-3') or (5'-TAT GAA ATC CCT CTG CAG CAT- $\left.3^{\prime}\right), \beta$-TrCP2 $\left(5^{\prime}\right.$-TCA TAC TGG AGG CAG AGG ACA- $3^{\prime}$ ), and NT shRNA ( $5^{\prime}$-AAA TGT ACT GCG CGT GGA GAC-3'). For RNAi-mediated silencing of $\mathrm{CK} 1 \varepsilon$ or $\beta$-TrCP in cultured hippocampal neurons, shRNA was cloned from the pcDNA 6.2-GW/EmGFP expression vector into a self-inactivating lentiviral vector pRRLsin. cPPT.CMV.eGFP.Wpre (Miyawaki et al., 2009; Noh et al., 2012). Hightiter vesicular stomatitis virus-pseudotyped lentiviral stocks were produced in HEK-293T cells as described previously (Miyawaki et al., 2009; Noh et al., 2012). In brief, cells were transfected with pRRL.PPT. hCMV.GFP.shRNA.Wpre transfer construct, pMDLg/pRRE and pRSVREV packaging constructs, and the envelope protein construct pMD2.G by means of calcium phosphate. Titers were determined by infecting HEK-293T cells with serial dilutions of concentrated lentivirus. eGFP fluorescence was evaluated by flow cytometry at $48 \mathrm{~h}$ after transduction; Titers were $1 \times 10^{9}$ transducing units. The efficacy of CK1 $\varepsilon$ and $\beta$-TrCP shRNA was evaluated by Western blot $7 \mathrm{~d}$ after transduction of primary hippocampal neurons prepared from the brains of E18 Sprague Dawley rats.

Histology and Fluoro-Jade labeling. Neuronal cell loss was assessed by histological examination of brain sections at the level of dorsal hippocampus from animals killed at $7 \mathrm{~d}$ after sham surgery or global ischemia. Animals were anesthetized with halothane and transcardially perfused using $0.9 \%$ saline with heparin followed by ice-cold $4 \%$ paraformaldehyde in PBS (0.1 M, pH 7.4). Brains were removed and immersed in fixative. Coronal sections $(20 \mu \mathrm{m})$ were cut at the level of the dorsal hippocampus with a cryotome and processed for staining with toluidine blue or Fluoro-Jade C (Millipore). The number of dying pyramidal neurons per $250 \mathrm{~mm}$ length of the medial CA1 region from approximately four to six rats per group (eight sections per rat) was counted under a fluorescence microscope at $40 \times$ magnification.

Western blots and immunoprecipitation. Western blot analysis was performed as described previously (Ofengeim et al., 2012; Rodenas-Ruano et al., 2012; Sehara et al., 2013). In brief, cells were washed with cold PBS and lysed in buffer containing the following (in mM): 25 Tris- $\mathrm{HCl}, \mathrm{pH}$ 7.4, $150 \mathrm{NaCl}, 1 \mathrm{EDTA}, 1 \times$ protease inhibitor mixture (Sigma), $0.1 \%$ SDS, and $0.5 \% \mathrm{Na}$ deoxycholate. For the tissue samples, hippocampi were rapidly dissected and transverse slices of dorsal hippocampus (1 $\mathrm{mm}$ ) were cut with a McIlwain tissue chopper. The CA1 or CA3 subfield was rapidly microdissected and lysed in buffer supplemented with a $1 \%$ mixture of protease inhibitors (Sigma). Protein concentrations were measured with the bicinchoninic acid assay (Pierce). Equal aliquots of 
protein $(50 \mu \mathrm{g})$ were subjected to SDS-PAGE (4-20\%), transferred to a nitrocellulose membrane, and processed for incubation with antibody (anti-REST, 1:1000, Millipore; anti-CK1 $\delta, 1: 500$, Santa Cruz Biotechnology; anti-CK1 $\varepsilon, 1: 1000$, BD Bioscience; anti- $\beta$-TrCP, 1:1000, antiubquitin, 1:1000, and anti-myc, 1:1000, Cell Signaling Technology; anti-Flag, 1:2000, Millipore; anti-HA, 1:1000, Covance; and anti- $\beta$-actin, 1:50000, Sigma). Membranes were washed and reacted with enhanced chemiluminescence reagent (GE Healthcare). For immunoprecipitation, $500-1000 \mu \mathrm{g}$ of lysates were incubated with the appropriate antibody (1-10 $\mu \mathrm{g}$ ) overnight at $4^{\circ} \mathrm{C}$ followed by $1 \mathrm{~h}$-incubation with Protein $\mathrm{G}$ Sepharose beads (Millipore). Immunocomplexes were washed five times with immunoprecipitation buffer containing the following (in $\mathrm{mM}$ ): 25 Tris-HCl, pH 7.4, $150 \mathrm{NaCl}, 1$ EDTA, 1 EGTA, and 0.5\% Triton X-100 before being resolved by SDS-PAGE and immunoblotted with the indicated antibodies. Band densities were normalized to $\beta$-actin. Mean band densities for samples from experimental animals were normalized to the corresponding samples from sham animals.

$q R T-P C R$. Cells were washed twice with cold PBS and RNA was extracted using TRIzol reagent (Invitrogen). RNA concentration was measured with a Nanodrop (NanoDrop Technologies). Aliquots of RNA (1 $\mu \mathrm{g})$ were reverse transcribed to cDNA with Superscript III Reverse Transcriptase (Invitrogen). Quantitative real-time PCR (qRT-PCR) was performed with TaqMan probes (Applied Biosystems) for REST (Hs00958503_m1); GAPDH (Hs02758991_g1) served as an endogenous reference. Reactions were run in triplicate in a StepOnePlus real-time PCR system (Applied Biosystems). mRNA abundance was calculated by means of the comparative Ct method at a threshold of 0.02. Relative expression ratios were calculated by normalization of values for experimental samples to those of the corresponding sham controls by means of the relative expression software tool (REST) on the basis of the group mean for the target transcript versus the reference GAPDH transcript (Pfaffl et al., 2002).

In vitro phosphorylation assay. To assess phosphorylation of REST, N2A cells were transfected with HA-conjugated WT and mutant REST using Lipofectamine 2000. Forty-eight hours after transfection, cells were rinsed with ice-cold PBS, pelleted by centrifugation, and lysed in lysis buffer. Lysates $(750 \mu \mathrm{g})$ were immunoprecipitated with anti-HA agarose conjugate (Sigma). Immunoprecipitated HA-REST was incubated with recombinant active CK1 $\delta$ (New England BioLabs) in a reaction mixture containing $1 \times$ assay buffer (50 mm HEPES, pH 7.4, $10 \mathrm{~mm} \mathrm{MgCl}, 1 \mathrm{~mm}$ EGTA, $0.4 \mathrm{~mm}$ DTT, and $1 \times$ protease inhibitor mixture, Sigma), $60 \mu \mathrm{M}$ Mg-ATP, $0.3 \mu \mathrm{Ci} \gamma^{32} \mathrm{P}$-ATP $(3000 \mathrm{Ci} / \mathrm{mmol}$; PerkinElmer), and 1 unit $/ \mu \mathrm{l} \mathrm{CK} 1 \delta$ at $30^{\circ} \mathrm{C}$ for $30 \mathrm{~min}$. The reaction was stopped by the addition of ice-cold radioimmune assay buffer containing the following (in mm): 10 Tris-HCl, pH 7.4, $75 \mathrm{NaCl}, 20$ EDTA, 10 EGTA, $20 \mathrm{Na}-$ pyrophosphate, $50 \mathrm{NaF}, 20$ glycerol-2-phosphate, and 1 -nitrophenylphosphate and stripped with loading buffer (Invitrogen). Samples were run on 3-8\% Tris-acetate gels (Invitrogen) for subsequent autoradiography and Western blotting.

Statistical analysis. For qRT-PCR, significance was assessed with the randomization test (Pfaffl et al., 2002) and a Student's $t$ test (unpaired, two-tailed). For Western band densities and radioactive band densities, significance was assessed with the Student's $t$ test (unpaired, two-tailed). $p<0.05$ was considered to be statistically significant.

\section{Results}

\section{CK1 regulates REST protein stability}

We first sought to identify the upstream kinase responsible for phosphorylation of residues critical to recognition of REST by $\beta$-TrCP, a member of the F-box family of E3 ligases, which initiates ubiquitination of many transcription factors and other target proteins. Toward this end, we used the protein kinase prediction algorithm Motif Scan set at low stringency (Obenauer et al., 2003). Among the protein kinases delineated by Motif Scan, CK1 was predicted to phosphorylate REST at S1027, a residue within the second degron motif. CK1 phosphorylates sites within or near the degron motifs of several other proteins, priming them for ubiquitin-based proteasomal degradation in a $\beta$-TrCP- dependent manner, including the transcription factor $\beta$-catenin (Cheong and Virshup, 2011); CDC25A, a phosphatase involved in cell division (Honaker and Piwnica-Worms, 2010); and UHRF1 (ubiquitin-like, with PHD and RING finger domains), an epigenetic protein involved in maintenance of DNA methylation during DNA replication (Chen et al., 2013).

To determine a possible role for CK1 in regulation of REST protein abundance, we used a combination of pharmacological and genetic approaches. HeLa cells express REST at high levels and are readily amenable to genetic manipulation. Application of the CK1 activator pyrvinium to HeLa cells decreased REST protein abundance in a dose-dependent manner (Fig. 1a). The CK1 inhibitors D4476 (Fig. 1b) and IC261 (data not shown) each increased REST expression. To rule out off-target effects, we investigated the ability of the inhibitor D4476 to block the effect of the activator pyrvinium. Application of D4476 (10 $\mu \mathrm{M})$ blocked the pyrvinium-induced increase in REST, indicating that pyrvinium does, as expected, act via CK1 (Fig. 1c). These findings indicate that CK1 activity negatively regulates REST expression. To determine whether CK1 abundance is causally related to REST protein abundance, we genetically manipulated CK1 and assessed the cellular levels of REST protein. Overexpression of Myc-tagged CK1 isoforms $\alpha 1, \alpha 2, \delta$, and $\varepsilon$ (but not $\gamma 1, \gamma 2$, or $\gamma 3$ ) decreased REST protein abundance, as assessed by Western blot analysis (Fig. 1d). Consistent with this, expression of shRNA constructs targeting CK1 $\delta$ ( $\sim 60 \%$ knock down), CK1 $\varepsilon(\sim 40 \%$ knock down), or a chained construct containing both shRNAs and thereby targeting CK1 $\delta$ and $\varepsilon$ (50\% knock down of CK $1 \delta ; 60 \%$ knock down of CK1 $1 \varepsilon$ ), but not NT shRNA, increased REST protein abundance (Fig. 1e). Collectively, these findings indicate that CK1 regulates REST protein expression in HeLa cells, but do not address whether CK1 regulates REST in neurons. To address this issue, we next examined the impact of CK1 on REST protein abundance in hippocampal neurons in vitro. Whereas activation of CK1 by pyrvinium decreased REST expression in neurons, inhibition or shRNA-mediated knock down of CK1 increased REST (Fig. 1f). To evaluate a possible role for other kinases in the regulation of REST protein levels, we examined the effect of inhibitors of other kinases on REST protein levels. Neither H89, an inhibitor of protein kinase A (Fig. $1 g$ ), nor LY294002, an inhibitor of PI3 kinase (Fig. 1h), significantly altered REST protein levels, indicating specificity of CK1 in regulation of REST expression.

The results thus far document a role for CK1 in REST protein expression, but do not address the mechanism by which CK1 may exert its effect. A reduction in protein could arise as a consequence of reduced protein synthesis and/or enhanced protein degradation. To determine whether CK1 regulates REST at the level of transcription, we examined the impact of the CK1 activator pyrvinium and the inhibitor D4476 on REST mRNA by qRTPCR. Neither pyrvinium nor D4476 detectably altered REST mRNA expression (Fig. 1i). Moreover, neither overexpression of myc-tagged CK $1 \alpha 1, \mathrm{CK} 1 \alpha 2, \mathrm{CK} 1 \delta$, CK $1 \varepsilon, \mathrm{CK} 1 \gamma 1, \mathrm{CK} 1 \gamma 2$, or CK1 $\gamma 3$ (Fig. $1 j$ ) nor shRNA-mediated knock down of CK1 $\delta$, $\mathrm{CK} 1 \varepsilon$, or CK1 $\delta$ and CK1 $\varepsilon$ (Fig. $1 k$ ) detectably altered REST mRNA, which is consistent with regulation at the posttranscriptional level. We next investigated whether CK1 regulates REST at the level of protein stability. Toward this end, we treated cells with the protein synthesis inhibitor cycloheximide $(100 \mu \mathrm{g} / \mathrm{ml})$ in the absence or presence of the CK1 activators pyrvinium or CK1 inhibitor D4476 and measured REST protein abundance over time. This protocol affords a measure of constitutive protein degradation. In the presence of cycloheximide, levels of REST 
a
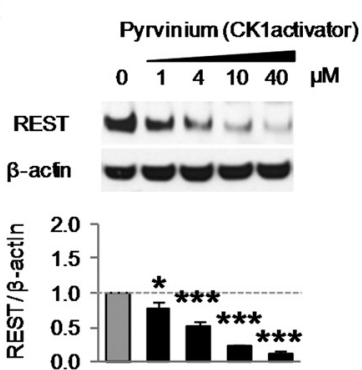

Pyrvinium $0 \quad 1 \quad 4 \quad 10 \quad 40(\mu \mathrm{M})$

d

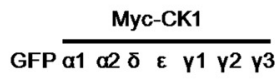

Myc $\mid$
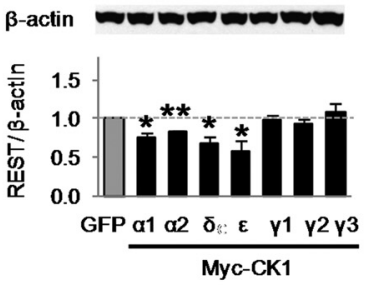

f

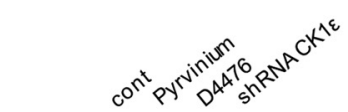

REST ㄴ. -

$\beta$-actin - - -
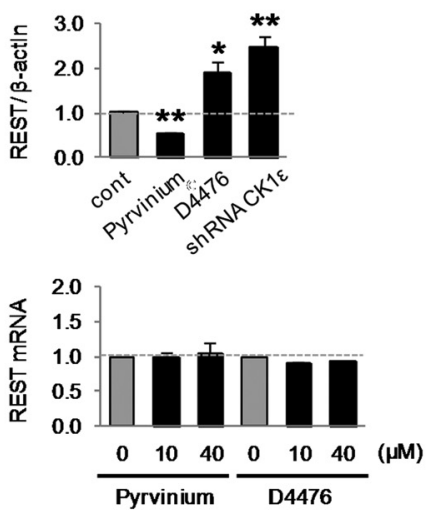

I

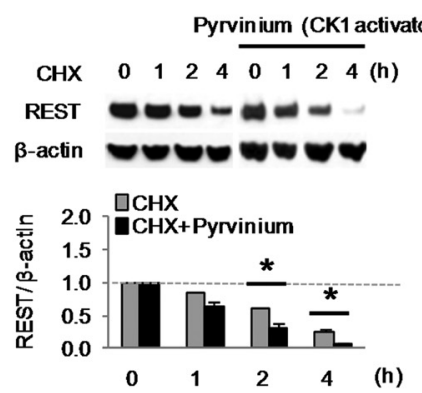

b

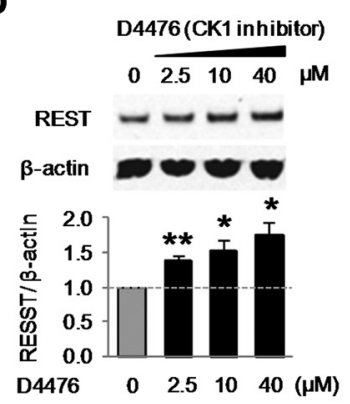

e

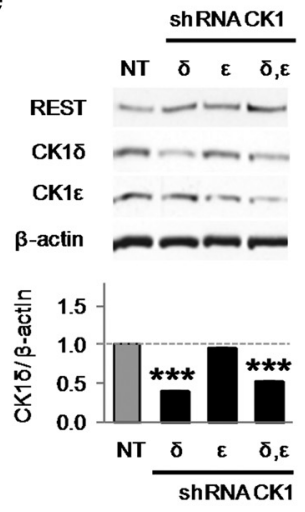

g

H89 (PKA inh ibitor)

$\begin{array}{lllll}0 & 2.5 & 10 & 40 & \mu \mathrm{M}\end{array}$

REST $=--$

$\beta$-actin $\approx \sim \approx$

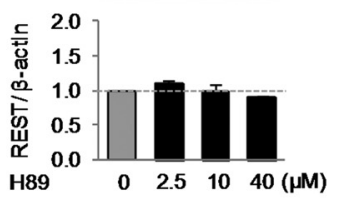

j

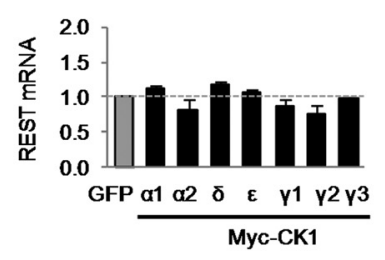

m

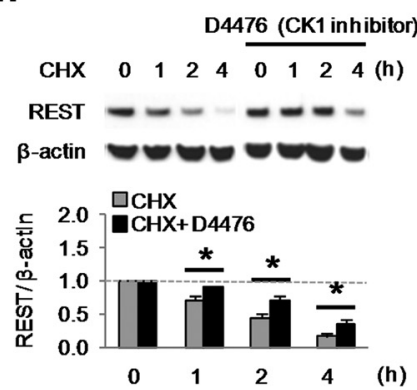

C
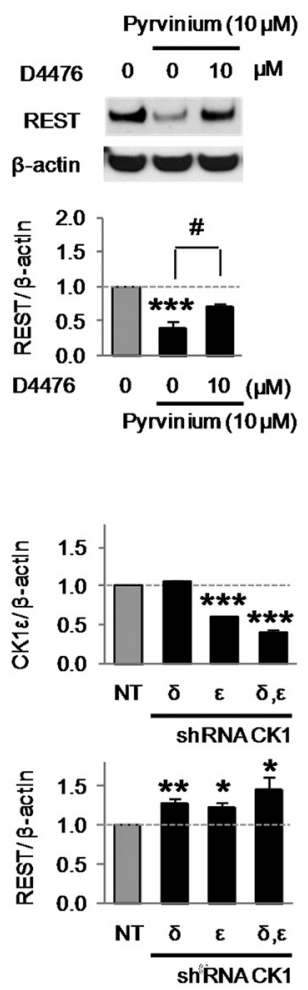

h

LY294002 (PI3K inhibitor)

$0 \longdiv { 6 . 2 5 2 5 1 0 0 \mu \mathrm { M } }$

REST ----

$\beta$-actin $\boldsymbol{\sigma} \omega \boldsymbol{\omega}$

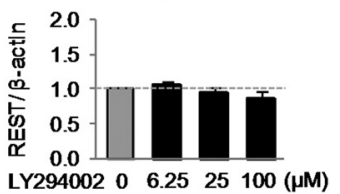

K

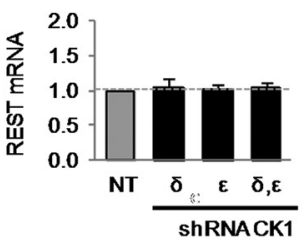

Figure 1. CK1 regulates REST by promoting protein degradation. $\boldsymbol{a}$, Top, Representative Western blot showing that the CK1 activator pyrvinium, reduces REST protein abundance in HeLa cells in a dose-dependent manner. Bottom, Summary data. $\boldsymbol{b}$, Top, Representative Western blot showing that the CK1 inhibitor D4476 increases REST protein abundance in a dose-dependent manner. Bottom, Summary data. c, Representative Western blot showing that pyrvinium reverses the increase in REST elicited by D4476. Bottom, summary data. $\boldsymbol{d}$, Top, Representative Western blot showing that overexpression of $\mathrm{CK} 1 \alpha 1, \mathrm{CK} 1 \alpha 2$, CK1 $\delta$, or CK1 $\varepsilon$, but not CK1 $\gamma 1$, CK1 $\gamma 2$, or CK1 $\gamma 3$, decreases REST protein abundance. Bottom, Summary data. $\boldsymbol{e}$, Top, (Figure legend continues.) 
protein declined. Whereas pyrvinium increased (Fig. 1l), D4476 attenuated (Fig. $1 \mathrm{~m}$ ) the rate of REST protein degradation. Collectively, these data indicate that CK1 negatively regulates REST abundance at the level of protein stability in HeLa cells and neurons.

\section{CK1 associates with and phosphorylates REST, thereby promoting $\beta$-TrCP-mediated ubiquitination}

$\beta$-TrCP recognizes and binds phosphorylated serine residues in canonical and noncanonical degron motifs within target proteins, directing them to ubiquitin-based proteasomal degradation (Frescas and Pagano, 2008; Chen et al., 2013). Humans and rats both express two $\beta$-TrCP genes, $\beta$-TrCP1 and $\beta$-TrCP2. Whereas both proteins are functional in humans, rats express a short, truncated $\beta$ - $\operatorname{TrCP} 2$, which lacks both the $\mathrm{D}$-domain and the F-box-like domain present in $\beta$ - $\operatorname{TrCP} 1$ and is therefore nonfunctional. We therefore focused on $\beta$-TrCP1. REST contains two neighboring, but distinct, degron motifs that serve as $\beta$-TrCP-binding sites, one containing E1009 and S1013 (Guardavaccaro et al., 2008) and the other containing S1024, S1027, and S1030 (Westbrook et al., 2008; Fig. 2a). Whereas it is known that phosphorylation of these serine residues is critical for recognition by $\beta-\operatorname{TrCP}$, the kinase that phosphorylates REST is as yet unknown. To address this issue, we first investigated whether CK1 physically associates with REST. CK1 $\varepsilon$ physically associated with endogenous REST, as assessed by coimmunoprecipitation (Fig. 2b).

To identify residues phosphorylated by CK1, we used sitedirected mutagenesis to mutate serine residues in and around the two degron motifs singly or in combination with the nonphosphorylatable residue alanine. WT and mutant HA-REST constructs were expressed in N2A cells and immunoprecipitated with an antibody directed to HA. N2A cells are a neuron-like cell that express very low levels of full-length REST and are therefore suitable for evaluation of mutant REST constructs. Immunocomplexes were subjected to an in vitro phosphorylation assay in the presence and absence of recombinant CK $1 \delta$. CK $1 \delta$ induced striking phosphorylation of WT REST (Fig. 2c). Several single point mutations (S1013A, S1024A, and S1030A) reduced CK1dependent phosphorylation of REST (Fig. 2c), which is consistent with the notion that loss of a single serine residue is sufficient to reduce REST phosphorylation. Importantly, the double REST mutant E1009A/S1013A and triple REST mutant S1024A/ S1027A/S1030A, which were shown by others to abolish $\beta$-TrCP binding (Guardavaccaro et al., 2008; Westbrook et al., 2008), also abolished CK1-dependent phosphorylation of REST (Fig. 2d). Moreover, two additional constructs, the double REST mutant

\footnotetext{
(Figure legend continued.) Representative Western blot showing that two shRNAs targeting different sequences in $C K 1 \delta$ and $C K 1 \varepsilon$, but not NT shRNA, increases REST protein abundance in HeLa cells. Bottom and right, Summary data. $\boldsymbol{f}$, Top, Representative Western blot showing that pyrvinium decreases and D4476 and shRNA to CK1 $\varepsilon$ increases REST protein levels in cultured hippocampal neurons Bottom, Summary data. $\boldsymbol{g}, \boldsymbol{h}$, Top, Representative Western blot showing that REST protein abundance is unchanged in HeLa cells treated with the PKA inhibitor H89 $(\boldsymbol{g})$ and the PI3 kinase (PI3K) inhibitor LY294002 (h). Bottom, Summary data. $\boldsymbol{i}-\boldsymbol{k}$, REST mRNA levels were unchanged in HeLa cells after treatment with pyrvinium or D4476 (i), myc-CK1 (j), or shRNA to CK1 $(\boldsymbol{k}) . \boldsymbol{I}, \boldsymbol{m}$, To monitor the impact of CK1 on the rate of protein degradation, HeLa cells were treated with pyrvinium $(10 \mu \mathrm{m}, \boldsymbol{I})$ or D4476 $(10 \mu \mathrm{m}, \boldsymbol{m})$ for $2 \mathrm{~h}$ before application of the protein synthesis inhibitor cycloheximide (100 $\mu \mathrm{g} / \mathrm{ml})$. At the indicated times, whole-cell lysates were prepared and immunoblots probed with REST or $\beta$-actin antibody. $n=3$ per treatment group in 3 independent experiments. Here and in Figures $2-4$, data represent mean \pm SEMs. ${ }^{* *} p<0.001 ;{ }^{* *},{ }^{\# \#} p<0.01 ;{ }^{*}, " p<0.05$.
}

S1013A/S1030A and the quadruple mutant S1013/S1024A/ S1027A/S1030A, each markedly reduced CK1-dependent phosphorylation (Fig. 2e). Importantly, CK1 increased association of $\beta$-TrCP with REST (Fig. 2f, top) and REST ubiquitination, as assessed by immunoprecipitation (Fig. $2 f$, bottom). Moreover, expression of two shRNA constructs targeting $\beta$ - TrCp1/2 $(\beta$ TrCp1/2 shRNA-1, $\sim 60 \%$ knock down; $\beta$-TrCp1/2 shRNA-2, $\sim 30 \%$ knock down), but not NT shRNA, markedly upregulated REST in hippocampal neurons (Fig. $2 g$ ), demonstrating an inverse causal relation between $\beta$-TrCp and REST. Collectively, these data demonstrate that CK1 phosphorylates all four serine residues contained within the two degron motifs of REST, increases association of $\beta$-TrCP with REST, and promotes ubiquitination of REST.

\section{REST is targeted to the proteasomal degradation pathway in neurons}

The results thus far demonstrate that CK1 is necessary and sufficient for phosphorylation of serine residues in the degron motifs within the REST C-terminal domain, association of $\beta$-TrCP with REST, and REST ubiquitination, but do not determine a role for proteasomal degradation of REST. Whereas $\beta$-TrCP-dependent proteasomal degradation in the regulation of REST in cancer cells and pluripotent and neural stem cells is well established (Frescas and Pagano, 2008; Chen et al., 2013), its role in the regulation of REST in neurons is as yet unclear. To address this issue, we first examined the impact of the proteasomal inhibitor lactacystin on REST abundance in the hippocampal CA1 under physiological conditions. Lactacystin injected directly into the CAl of control animals increased REST abundance and enhanced global protein ubiquitination in the CA1, which is consistent with a role for proteasomal degradation in maintenance of REST at low, constitutive levels in adult neurons under physiological conditions (Fig. 3a).

\section{Targeting of REST for proteasomal degradation is blunted in insulted neurons}

We next investigated a role for proteasomal degradation in the regulation of REST abundance in insulted neurons. Neuronal insults such as global ischemia increase REST protein expression and induce silencing of target genes such as GluA2, which in turn leads to an increase in GluA2-lacking, $\mathrm{Ca}^{2+}$-permeable AMPARs in selectively vulnerable hippocampal neurons, events causally related to neuronal death (Oguro et al., 1999; Calderone et al., 2003; Liu et al., 2004; Noh et al., 2005; Noh et al., 2012). This is significant in that GluA2-lacking AMPARs are implicated in ischemia-induced neuronal death. We induced OGD, an in vitro model of global ischemia, in hippocampal neurons in vitro. Under control conditions, application of the proteasomal inhibitor lactacystin did not detectably alter $\beta$-TrCP, but increased REST and decreased the REST target gene GluA2. OGD induced downregulation of $\beta$-TrCP, upregulation of REST, and downregulation of GluA2. In neurons subjected to OGD, application of lactacystin did not alter $\beta$-TrCP or further alter REST or GluA2 (Fig. $3 b$ ). Under control conditions, $\beta$-TrCP associated with REST. OGD induced a marked dissociation of $\beta$-TrCP from REST, as assessed by coimmunoprecipitation (Fig. 3c). These findings (together with the data shown in Figs. $1 f, 2 g$ ) demonstrate that ischemic insults upregulate REST in hippocampal neurons via $\beta$-TrCP-mediated, ubiquitin-based proteasomal degradation. 
a

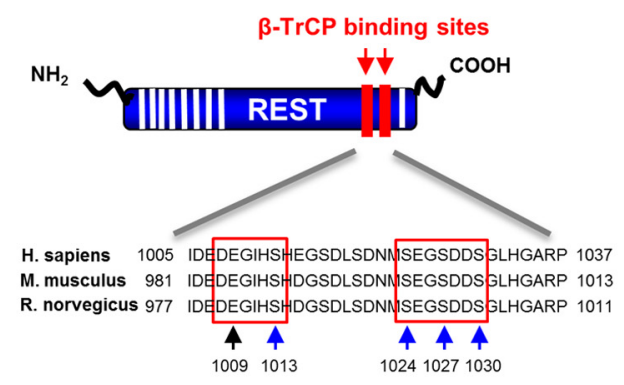

CK1 phosphorylation sites

C

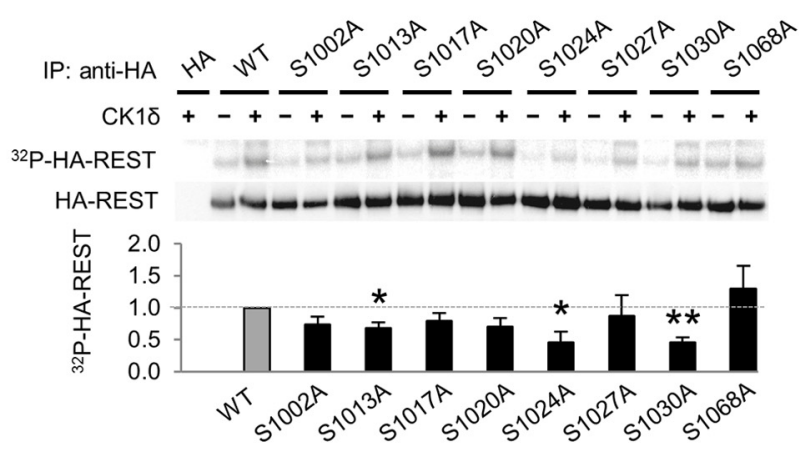

b

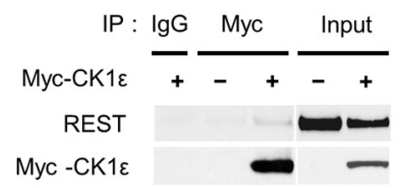

d

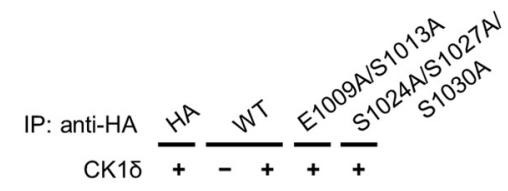

32P-HA-REST

HA-REST घᄇーレ

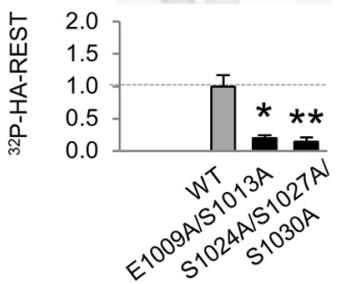

e

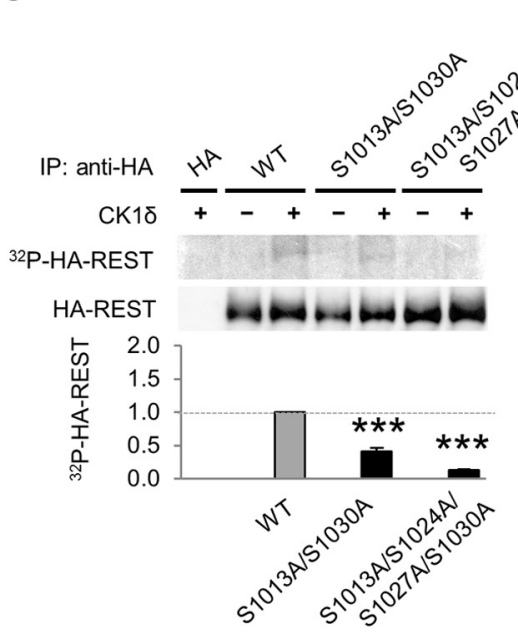

f

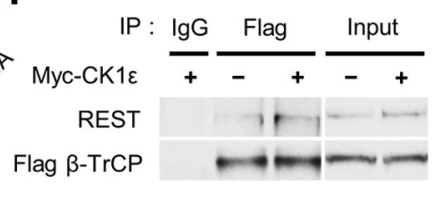

g

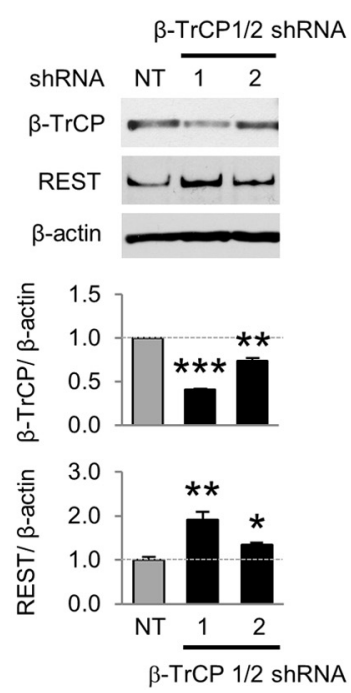

Figure 2. CK1 associates with and phosphorylates REST and increases $\beta$-TrCP binding and REST ubiquitination. $\boldsymbol{a}$, Diagram illustrating phosphorylated serine residues within two noncanonical degron motifs harbored within the REST C terminus that are critical to recognition by $\beta$-TrCP. $\boldsymbol{b}$, Coimmunoprecipitation of recombinant Myc from HeLa cells expressing Myc-CK1 $\varepsilon$ and probed for REST showing that Myc-CK1 $\varepsilon$ associates with endogenous REST. c, Immunoprecipitation of HA from N2A cells expressing WT or mutant HA-REST constructs incubated in the presence or absence of recombinant CK1 $\delta$ and $\gamma$ - ${ }^{32}$ P-ATP. Top, Autoradiogram depicting phospho-HA-REST showing that single-point mutations S1013A, S1024A, and S1030A significantly alter CK1-dependent phosphorylation of REST. Bottom, Summary data. Values for phosphorylated HA-REST are normalized to values for HA-REST. $\boldsymbol{d}$, Immunoprecipitation of HA from N2A cells expressing WT HA-REST, double mutant HA-REST (E1009A/S1013A), and triple mutant HA-REST (S1024A/S1027A/S1030A) incubated in the presence or absence of recombinant CK1 $\delta$ and $\gamma^{-32}{ }^{32}$-ATP. Top, Autoradiogram depicting phospho-HA-REST shows that the double and triple HA-REST mutants abolish CK1-dependent phosphorylation. Bottom, Summary data. $\boldsymbol{e}$, Immunoprecipitation of HA from N2A cells expressing WT HA-REST, double mutant HA-REST (S1013A/S1030A), or quadruple mutant HA-REST (S1013A/S1024A/S1027A/ S1030A) with an antibody to HA was incubated in the presence or absence of recombinant CK1 $\delta$ and $\gamma^{-}{ }^{32}$ P-ATP. Top, Autoradiogram depicting phosphoHA-REST showing that the double and quadruple HA-REST mutants significantly decrease CK1-dependent phosphorylation of REST. Bottom, Summary data. $\boldsymbol{f}$, Top, Immunoprecipitation of Flag from HeLa cells expressing myc-CK1 $\varepsilon$ and Flag- $\beta$-TrCP subjected to Western blots probed for endogenous REST showing that CK1 increases the interaction between REST and $\beta$-TrCP. Bottom, Immunoprecipitation of endogenous REST from HeLa cells expressing Myc-CK1 $\varepsilon$ was subjected to Westerns and probed for REST, Myc-CK1 $\varepsilon$, and ubiquitin showing that CK1 binds REST and promotes ubiquitination of REST. $g$, Top, Representative Western blot showing that two different sequences of shRNA-mediated knock down of $\beta$-TrCP1/2 $\left(\beta\right.$-TrCP1/2 shRNA-1, $\beta$-TrCP1/2 shRNA-2) in hippocampal neurons increase REST expression. Bottom, Summary data. $n=3$ per treatment group in 3 independent experiments. ${ }^{* * *} p<$ $0.001 ;{ }^{* *} p<0.01 ;{ }^{*} p<0.05$. 
Global ischemia decreases CK1 and $\boldsymbol{\beta}$-TrCP and promotes upregulation of REST in the CA1

To determine a role for CK1 and ubiquitin-based proteasomal degradation in upregulation of REST in the hippocampal CA1 in a clinically relevant model of global ischemia, we subjected animals to global ischemia in vivo. Global ischemia induced by four-vessel occlusion (10 $\mathrm{min}$ ) in rats causes selective, delayed neuronal death and delayed cognitive deficits (for review, see Ofengeim et al., 2011). Pyramidal neurons in the hippocampal CA1 are particularly vulnerable. Histological evidence of degeneration is not observed until 2-3 d after ischemia, affording a substantial window of time for molecular studies. We evaluated $\mathrm{CK} 1 \delta, \mathrm{CK} 1 \varepsilon$, $\beta$-TrCP, Cul1, and HAUSP expression in the CA1 of animals subjected to global ischemia or sham operation. Cull is a component of the SCF (SKP1-CUL1-Fbox protein) ubiquitin ligase complex (Frescas and Pagano, 2008). HAUSP is a deubiquitylase known to stabilize REST (Huang et al., 2011). Under basal conditions, $\mathrm{CK} 1 \delta, \mathrm{CK} 1 \varepsilon, \beta$-TrCP, Cul1, and HAUSP were robustly expressed in the CA1 of adult rats. In contrast, REST was detectable, but at very low levels. Global ischemia markedly reduced $\mathrm{CK} 1 \delta, \mathrm{CK} 1 \varepsilon$, and $\beta$-TrCP protein abundance, with little or no change in Cull or HAUSP. In contrast, ischemia markedly increased REST protein abundance in the CA1 (Fig. $4 a, b)$. The changes in $\mathrm{CK} 1, \beta-\operatorname{TrCP}$, and REST were subfield specific in that expression was not altered in the resistant CA3 (Fig. 4c,d).

\section{CK1 activation protects against} ischemia-induced neuronal death

To determine whether loss of $\mathrm{CK} 1$ is causally related to ischemia-induced upregulation of REST and neuronal death, we examined the ability of CK1 activation to repress REST and rescue CA1 neurons from ischemia-induced neuronal death. Toward this end, we injected the CK1 activator pyrvinium intracerebroventricularly immediately after induction of global ischemia in vivo. Whereas rats subjected to global ischemia exhibited robust neuronal death in the CA1 $7 \mathrm{~d}$ after insult, as assessed by histology and Fluoro-Jade staining (Fig. 4e,f), neuronal death was significantly reduced in rats injected with pyrvinium immediately after ischemia. To investigate a possible mechanism for the CK1-activator-induced neuroprotection, we analyzed the impact of pyrvinium on $\beta$-TrCP, REST, and GluA2 protein levels in the CA1 of rats subjected to global ischemia. Pyrvinium rescued, at least in part, the ischemia-induced decrease in $\beta$-TrCP, the increase in REST, and the decrease in GluA2 (Fig. $4 g, h$ ), which is consistent with a model whereby CK1 promotes $\beta$-TrCP stability by association with REST, targeting of REST for proteasomal degradation, and unsilencing of GluA2. a
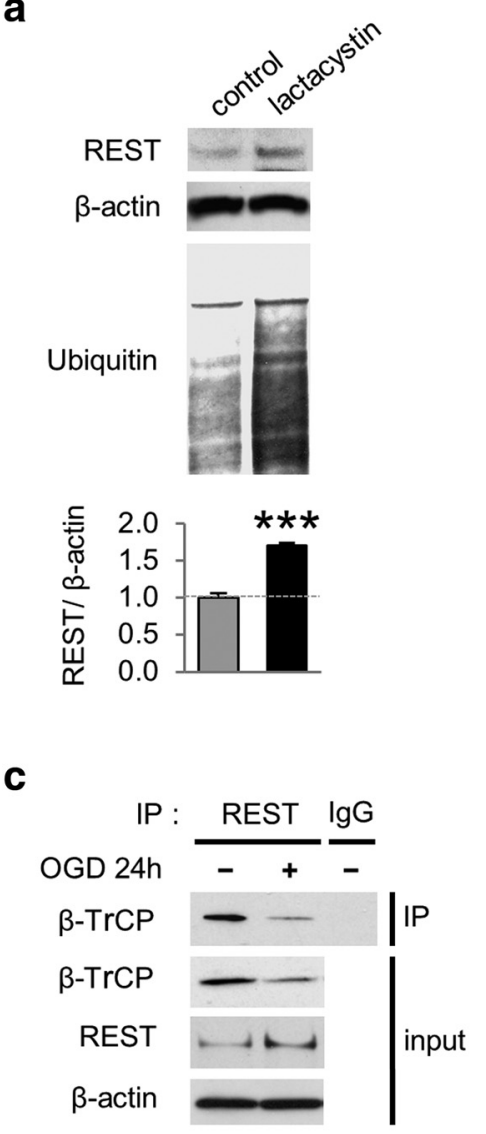

b

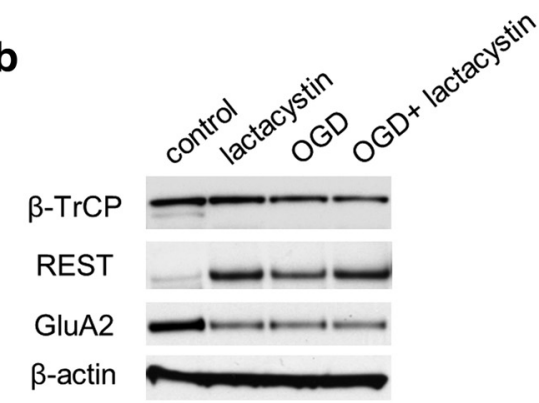

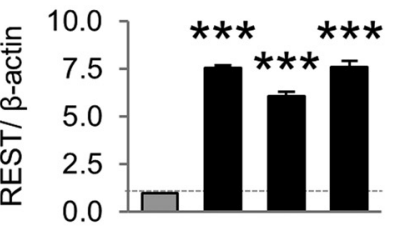

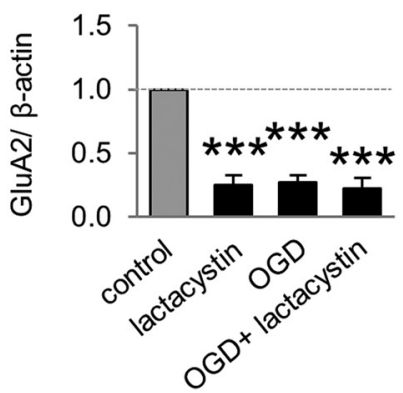

Figure 3. REST is targeted to the proteasomal degradation pathway in neurons. $\boldsymbol{a}$, Top, Representative Western blot showing that the proteasome inhibitor lactacystin injected in vivo increases REST abundance and global protein ubiquitination in the and downregulation of the REST target gene GluA2 under control conditions. OGD decreases $\beta$-TrCP, increases REST, and decreases GluA2 in hippocampal neurons in vitro. Administration of lactacystin to neurons subjected to OGD does not further alter REST or GluA2. Bottom, Summary data. $n=3$ per treatment group in 3 independent experiments. $c$, Coimmunoprecipitation of endogenous REST from control hippocampal neurons or neurons subjected to OGD showing that endogenous REST associates with endogenous $\beta$ - $\operatorname{TrCP}$ under control conditions and that $0 \mathrm{GD}$ promotes dissociation of REST from $\beta$ - $\operatorname{TrCP}$. ${ }^{* * *} p<0.001$.

These findings demonstrate an inverse causal relation between CK1 and neuronal death of CA1 neurons and implicate CK1 as a putative target for therapeutic intervention in ischemic stroke.

\section{Discussion}

In the present study, we show that REST is regulated at the level of protein stability via $\beta$-TrCP-dependent, ubiquitin-based proteasomal degradation in differentiated neurons under physiological conditions and identify CK1 as an upstream effector that bidirectionally regulates REST cellular abundance. CK1 associates with and phosphorylates REST at two neighboring, but distinct, motifs within the $\mathrm{C}$ terminus of REST that are essential to binding by $\beta$-TrCP (the degron motifs), thereby priming REST for ubiquitin-based proteasomal degradation. Activation or overexpression of CK1 promotes REST ubiquitination and degradation in a $\beta$-TrCP-dependent manner. Inhibition or RNAi-mediated knock down of CK1 promotes REST stability and increases REST 
a

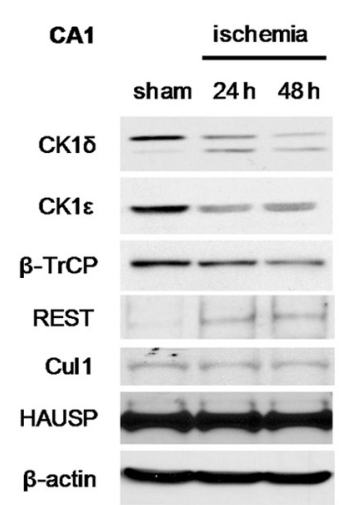

C

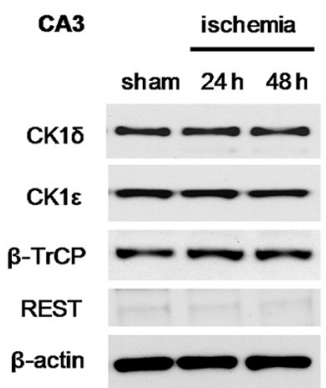

b
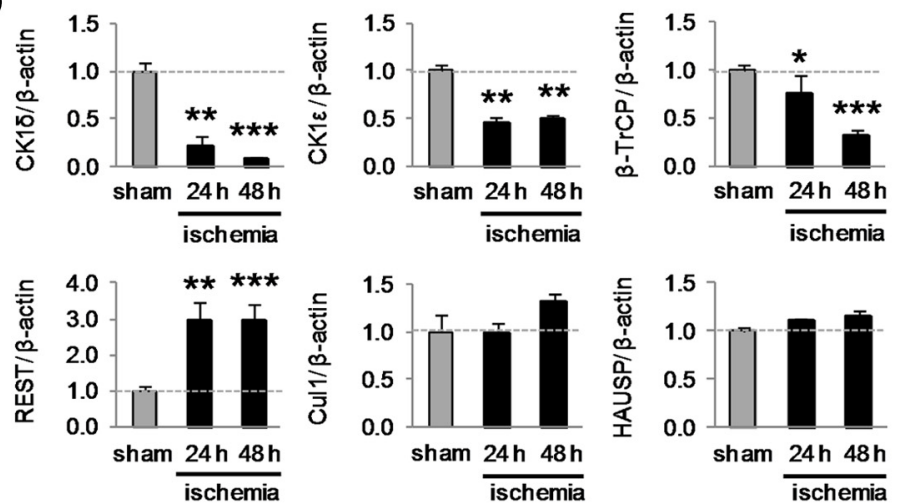

d
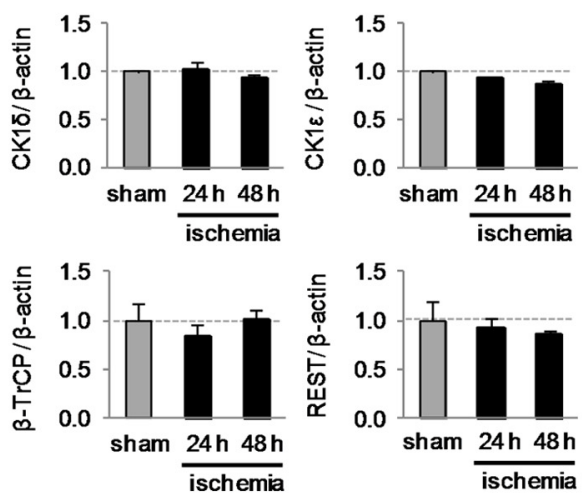

e sham
sham
+ pyrvinium
(CK1 activator)
ischemia
ischemia
+ pyrvinium
(CK1 activator)

g

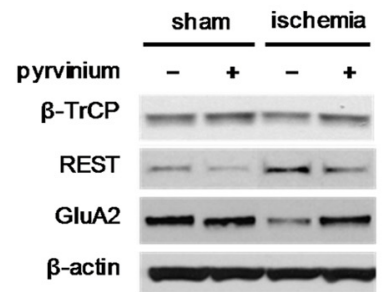

Toluidine blue
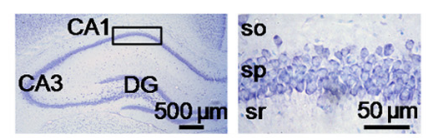

$50 \mu \mathrm{m}$
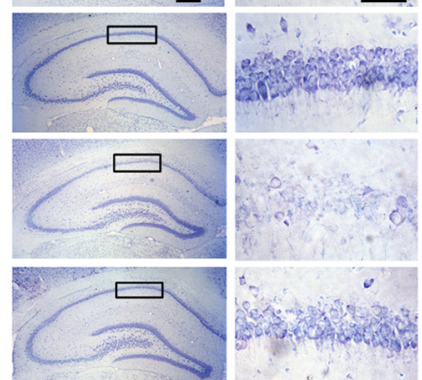

h
Fluoro-Jade

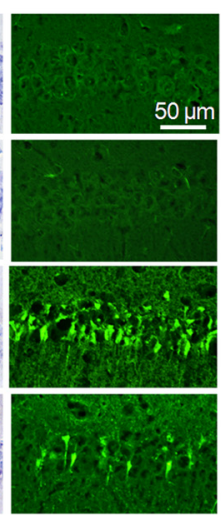

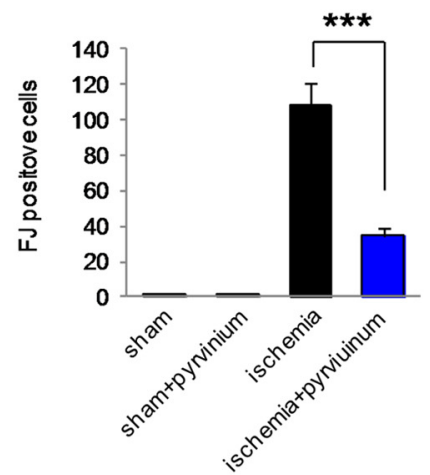
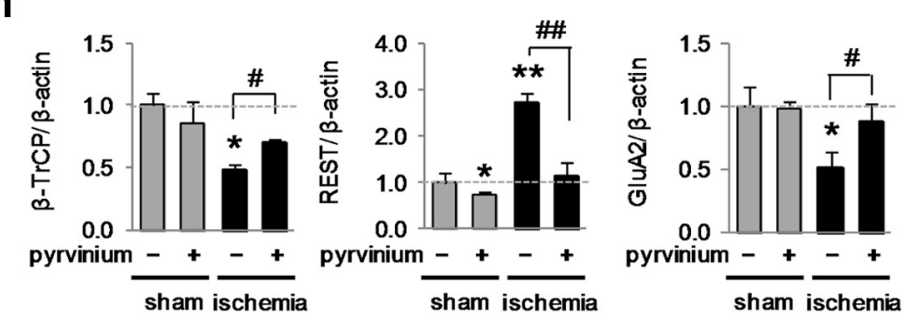

Figure 4. The CK1 activator pyrvinium protects CA1 neurons from ischemia-induced cell death in vivo. $\boldsymbol{a}$, Representative Western blot showing that global ischemia induces a decrease in CK1 $\delta$, CK1 $\varepsilon$, and $\beta$-TrCP and an increase in REST, but does not detectably alter Cul1 or HAUSP protein expression in the CA1 assessed at 24 and 48 h after ischemia. $\boldsymbol{b}$, Summary data. $\boldsymbol{c}$, Representative Western blot showing that global ischemia does not alter $\mathrm{CK} 1 \delta, C K 1 \varepsilon, \beta$-TrCP, or REST protein expression in the CA3 assessed at 24 and $48 \mathrm{~h}$ after ischemia. $\boldsymbol{d}$, Summary data. $\boldsymbol{e}$, Representative images of toluidine blue and Fluoro-Jade staining of CA1 pyramidal neurons in rats $7 \mathrm{~d}$ after global ischemia or sham surgery, followed by intracerebroventricular injection of the CK1 activator pyrvinium (1 mm) or vehicle. Scale bars: Iow magnification, $500 \mu \mathrm{m}$; high magnification, $50 \mu \mathrm{m}$. $f$, Quantification of dying CA1 pyramidal neurons as assessed by Fluoro-Jade staining ( $n=5-6$ animals per group). Pyrvinium rescues ischemia-induced neuronal death in the CA1. $\boldsymbol{g}$, Representative Western blot showing that injection of pyrvinium partially restores the ischemia-induced decrease in $\beta$ - $\operatorname{Tr} C P$ and essentially fully reverses the increase in REST and decrease in the REST target GluA2. $\boldsymbol{h}$, Summary data. $n=4-6$ animals per treatment group. ${ }^{* * *} p<0.001 ;{ }^{* *}, " \# p 0.01 ;{ }^{*}, " p<0.05$. 


\section{Physiological conditions in neurons}

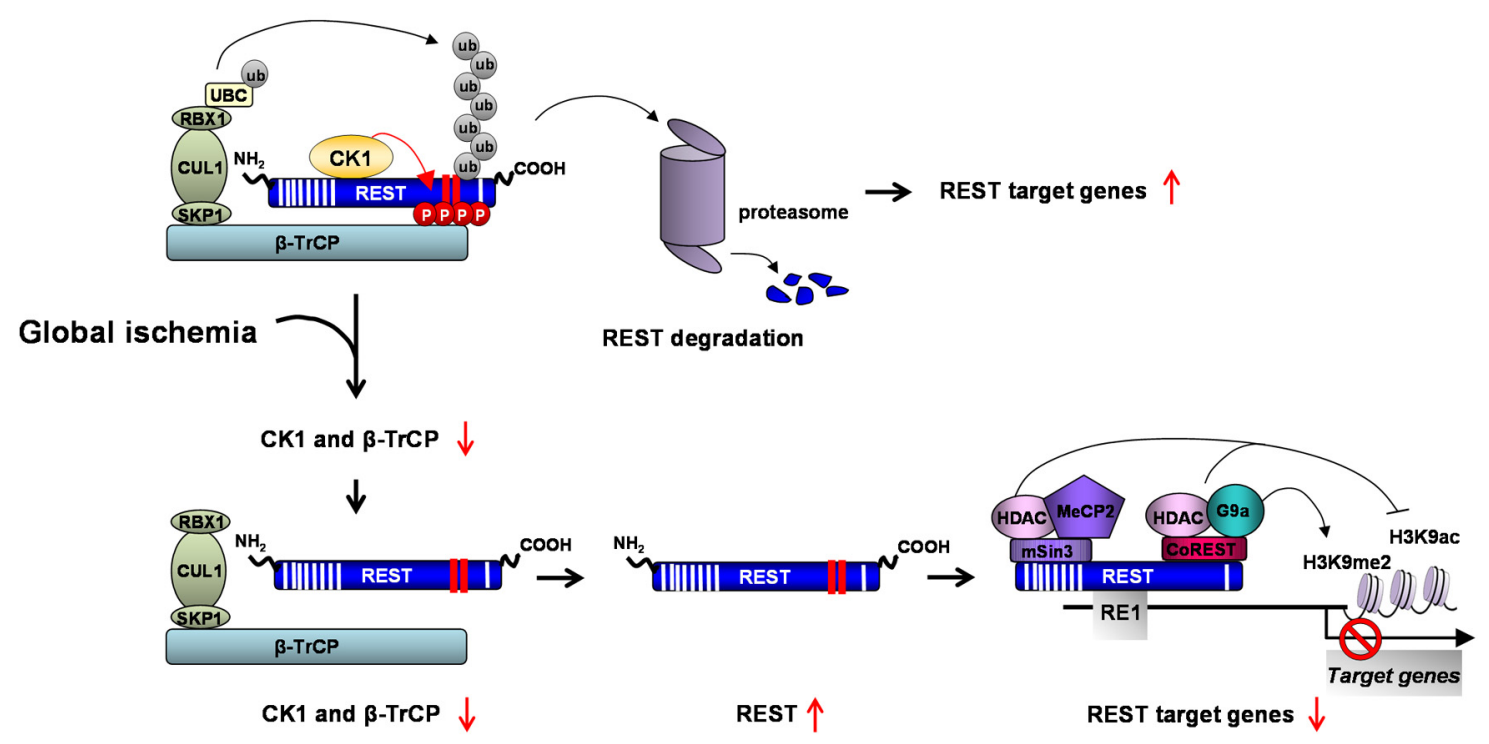

Figure 5. Model depicting a hypothetical mechanism by which CK1 regulates REST abundance in differentiated neurons under physiological and pathological conditions. Under physiological conditions, CK1 binds and phosphorylates REST at sites within two neighboring, but distinct, degron motifs. The phosphorylated degrons (phospho-degrons) are critical to recognition of REST by the E3 ubiquitin protein ligase $\beta$-TrCP, which ubiquitinates and targets REST for proteasomal degradation. Global ischemia reduces $\mathrm{CK} 1$ and $\beta$ - $\operatorname{TrCP}$ abundance, which leads to an increase in REST in the hippocampal CA1. REST binds to the RE1 element within the promoter of target genes such as GluA2 and orchestrates the assembly of mSin3A and COREST, HDACS 1 and 2, G9a, and MeCP2. The REST- corepressor complex promotes epigenetic remodeling of core histone proteins at the promoter of target genes and represses transcription of synaptic proteins. (Modified with permission from Frescas and Pagano, 2008; Noh et al., 2012).

cellular levels. These findings establish an inverse causal relation between CK1 and REST abundance. We further show that ischemia triggers a decrease in $\mathrm{CK} 1$ and $\beta$-TrCP and an increase in REST in selectively vulnerable CA1 pyramidal neurons. This is significant in that activation of REST is causally linked to ischemia- and seizure-induced neuronal death. A single, acute injection of the CK1 activator pyrvinium to rats immediately after an ischemic episode restores CK 1 and $\beta$-TrCP, decreases REST, and rescues CA1 neurons destined to die. Collectively, these results identify a novel and previously unappreciated role for CK1 as a brake on REST stability and abundance in adult neurons and reveal that loss of CK1 is causally related to neuronal death in a clinically relevant model of global ischemia. To our knowledge, this is the first demonstration that REST is regulated by proteasomal degradation in mature neurons and that CK1 regulates REST expression in any cell type.

The findings in the present study are consistent with a model whereby REST is normally quiescent, but can be reactivated in differentiated neurons during postnatal development in an experience-dependent manner (Rodenas-Ruano et al., 2012) and in response to neuronal insults such as ischemia (Calderone et al., 2003; Formisano et al., 2007; Noh et al., 2012) and seizures (Palm et al., 1998; Huang et al., 2002). Under physiological conditions, CK1 (the upstream effector) maintains REST at low, constitutive levels in differentiated neurons. CK1 associates with and phosphorylates REST (the substrate) at specific serine residues within the two degron motifs, enabling recognition by the E3 ligase $\beta$-TrCP (Fig. 5). Upon binding, $\beta$-TrCP polyubiquitinates the substrate, priming it for ubiquitin-based proteasomal degradation. Ischemic insults blunt $\mathrm{CK} 1$ and $\beta$-TrCP, inducing upregulation of REST in selectively vulnerable hippocampal neurons. Upon activation, REST binds to the RE1 element within the promoter of target genes important to synaptic function, such as GluA2, and orchestrates the assembly of the corepressor complex (mSin3A and CoREST, HDACs 1 and 2, G9a, and MeCP2). The corepressor complex promotes epigenetic remodeling of core histone proteins at the promoter of target genes and represses transcription of genes important to synaptic plasticity and neuronal survival.

The present study sheds light on the mechanism by which CK1 regulates REST cellular levels. CK1 associates with REST and phosphorylates all four serine residues in its two degron motifs, enabling binding of $\beta$-TrCP and activation of ubiquitin-based proteasomal degradation. Importantly, both the double mutant E1009A/S1013A and the triple mutant S1024A/S1027A/S1030A, which were shown by others to abolish $\beta$-TrCP binding (Guardavaccaro et al., 2008; Westbrook et al., 2008), also abolish CK1dependent phosphorylation of REST, which is consistent with a cooperative/synergistic interaction between the two motifs. Interestingly, we found that loss of individual serine residues within or in close proximity to the degron motifs is sufficient to reduce CK1-dependent phosphorylation of REST. Our findings do not, however, preclude the possibility that, not only CK1, but also other protein kinases, phosphorylate serine residues within the degron motifs and thereby regulate REST abundance in differentiated neurons. In addition, our findings do not rule out the possibility that other signaling proteins regulated by CK1 (e.g., $\beta$-catenin) contribute to the neuroprotective effects of pyrvinium in global ischemia. CK1 phosphorylates $\beta$-catenin, priming it for subsequent phosphorylation by glycogen synthase kinase- 3 and targeting of $\beta$-catenin for ubiquitin-based proteasomal degradation (Cheong and Virshup, 2011). Whereas the prevailing view is that CK1 is constitutively active, recent findings identify DEAD-box RNA helicase (DDX3) as an essential upstream regulator of CK1 $\varepsilon$ and Wnt- $\beta$-catenin signaling (Cruciat et al., 2013), raising the possibility that DDX3 may serve to regulate other CK1 targets such as REST.

The present findings have broad implications for amelioration of the neurodegeneration and cognitive deficits associated with ischemic stroke. Importantly, dysregulation of REST and its 
target genes are implicated not only in ischemia, but also in the pathogenesis of medulloblastomas, epilepsy, Huntington's disease, and SMCX, a form of X-linked mental retardation (Ballas and Mandel, 2005; Ooi and Wood, 2007; Hwang et al., 2013). Therefore, our findings implicate CK1 as a therapeutic target, not only for ischemic injury, but also for other brain disorders that involve dysregulation of REST in neurons.

\section{References}

Ballas N, Mandel G (2005) The many faces of REST oversee epigenetic programming of neuronal genes. Curr Opin Neurobiol 15:500-506. CrossRef Medline

Ballas N, Grunseich C, Lu DD, Speh JC, Mandel G (2005) REST and its corepressors mediate plasticity of neuronal gene chromatin throughout neurogenesis. Cell 121:645-657. CrossRef Medline

Calderone A, Jover T, Noh KM, Tanaka H, Yokota H, Lin Y, Grooms SY, Regis R, Bennett MV, Zukin RS (2003) Ischemic insults de-repress the gene silencer rest in neurons destined to die. J Neurosci 23:2112-2121. Medline

Chen H, Ma H, Inuzuka H, Diao J, Lan F, Shi YG, Wei W, Shi Y (2013) DNA damage regulates UHRF1 stability via the SCF(beta-TrCP) E3 ligase. Mol Cell Biol 33:1139-1148. CrossRef Medline

Cheong JK, Virshup DM (2011) Casein kinase 1: complexity in the family. Int J Biochem Cell Biol 43:465-469. CrossRef Medline

Chergui K, Svenningsson P, Greengard P (2005) Physiological role for casein kinase 1 in glutamatergic synaptic transmission. J Neurosci 25:66016609. CrossRef Medline

Cruciat CM, Dolde C, de Groot RE, Ohkawara B, Reinhard C, Korswagen HC, Niehrs C (2013) RNA helicase DDX3 is a regulatory subunit of casein kinase 1 in Wnt-beta-catenin signaling. Science 339:1436-1441. CrossRef Medline

Formisano L, Noh KM, Miyawaki T, Mashiko T, Bennett MV, Zukin RS (2007) Ischemic insults promote epigenetic reprogramming of mu opioid receptor expression in hippocampal neurons. Proc Natl Acad Sci U S A 104:4170-4175. CrossRef Medline

Frescas D, Pagano M (2008) Deregulated proteolysis by the F-box proteins SKP2 and beta-TrCP: tipping the scales of cancer. Nat Rev Cancer 8:438449. CrossRef Medline

Guardavaccaro D, Frescas D, Dorrello NV, Peschiaroli A, Multani AS, Cardozo T, Lasorella A, Iavarone A, Chang S, Hernando E, Pagano M (2008) Control of chromosome stability by the beta-TrCP-REST-Mad2 axis. Nature 452:365-369. CrossRef Medline

Honaker Y, Piwnica-Worms H (2010) Casein kinase 1 functions as both penultimate and ultimate kinase in regulating Cdc25A destruction. Oncogene 29:3324-3334. CrossRef Medline

Huang Y, Doherty JJ, Dingledine R (2002) Altered histone acetylation at glutamate receptor 2 and brain-derived neurotrophic factor genes is an early event triggered by status epilepticus. J Neurosci 22:8422-8428. Medline

Huang Z, Wu Q, Guryanova OA, Cheng L, Shou W, Rich JN, Bao S (2011) Deubiquitylase HAUSP stabilizes REST and promotes maintenance of neural progenitor cells. Nat Cell Biol 13:142-152. CrossRef Medline

Hwang JY, Aromolaran KA, Zukin RS (2013) Epigenetic mechanisms in stroke and epilepsy. Neuropsychopharmacology 38:167-182. CrossRef Medline

Liu F, Virshup DM, Nairn AC, Greengard P (2002) Mechanism of regulation of casein kinase I activity by group I metabotropic glutamate receptors. J Biol Chem 277:45393-45399. CrossRef Medline

Liu S, Lau L, Wei J, Zhu D, Zou S, Sun HS, Fu Y, Liu F, Lu Y (2004) Expression of $\mathrm{Ca}(2+)$-permeable AMPA receptor channels primes cell death in transient forebrain ischemia. Neuron 43:43-55. CrossRef Medline

Miyawaki T, Ofengeim D, Noh KM, Latuszek-Barrantes A, Hemmings BA, Follenzi A, Zukin RS (2009) The endogenous inhibitor of Akt, CTMP, is critical to ischemia-induced neuronal death. Nat Neurosci 12:618-626. CrossRef Medline

Noh KM, Yokota H, Mashiko T, Castillo PE, Zukin RS, Bennett MV (2005)
Blockade of calcium-permeable AMPA receptors protects hippocampal neurons against global ischemia-induced death. Proc Natl Acad Sci U S A 102:12230-12235. CrossRef Medline

Noh KM, Hwang JY, Follenzi A, Athanasiadou R, Miyawaki T, Greally JM, Bennett MV, Zukin RS (2012) Repressor element-1 silencing transcription factor (REST)-dependent epigenetic remodeling is critical to ischemia-induced neuronal death. Proc Natl Acad Sci U S A 109:E962E971. CrossRef Medline

Obenauer JC, Cantley LC, Yaffe MB (2003) Scansite 2.0: Proteome-wide prediction of cell signaling interactions using short sequence motifs. Nucleic Acids Res 31:3635-3641. CrossRef Medline

Ofengeim D, Miyawaki T, Zukin RS (2011) Molecular and cellular mechanisms of ischemia-induced neuronal death. In: Stroke: pathophysiology, diagnosis and management (Mohr JP, Wolf P, Grotta JC, Moskowitz MA, Mayberg M, von Kummer R, eds), pp 1-39. Philadelphia: Churchill Livingstone Elsevier.

Ofengeim D, Chen YB, Miyawaki T, Li H, Sacchetti S, Flannery RJ, Alavian KN, Pontarelli F, Roelofs BA, Hickman JA, Hardwick JM, Zukin RS, Jonas EA (2012) N-terminally cleaved Bcl-xL mediates ischemia-induced neuronal death. Nat Neurosci 15:574-580. CrossRef Medline

Oguro K, Oguro N, Kojima T, Grooms SY, Calderone A, Zheng X, Bennett MV, Zukin RS (1999) Knockdown of AMPA receptor GluR2 expression causes delayed neurodegeneration and increases damage by sublethal ischemia in hippocampal CA1 and CA3 neurons. J Neurosci 19:92189227. Medline

Ooi L, Wood IC (2007) Chromatin crosstalk in development and disease: lessons from REST. Nat Rev Genet 8:544-554. CrossRef Medline

Palm K, Belluardo N, Metsis M, Timmusk T (1998) Neuronal expression of zinc finger transcription factor REST/NRSF/XBR gene. J Neurosci 18: 1280-1296. Medline

Pfaffl MW, Horgan GW, Dempfle L (2002) Relative expression software tool (REST) for group-wise comparison and statistical analysis of relative expression results in real-time PCR. Nucleic Acids Res 30:e36. CrossRef Medline

Polakis P (2002) Casein kinase 1: a Wnt'er of disconnect. Curr Biol 12: R499-R501. CrossRef Medline

Price MA (2006) CKI, there's more than one: casein kinase I family members in Wnt and Hedgehog signaling. Genes Dev 20:399-410. CrossRef Medline

Qureshi IA, Mehler MF (2009) Regulation of non-coding RNA networks in the nervous system-what's the REST of the story? Neurosci Lett 466:7380. CrossRef Medline

Rodenas-Ruano A, Chávez AE, Cossio MJ, Castillo PE, Zukin RS (2012) REST-dependent epigenetic remodeling promotes the developmental switch in synaptic NMDA receptors. Nat Neurosci 15:1382-1390. CrossRef Medline

Sehara Y, Sawicka K, Hwang JY, Latuszek-Barrantes A, Etgen AM, Zukin RS (2013) Survivin Is a transcriptional target of STAT3 critical to estradiol neuroprotection in global ischemia. J Neurosci 33:12364-12374. CrossRef Medline

Singh A, Rokes C, Gireud M, Fletcher S, Baumgartner J, Fuller G, Stewart J, Zage P, Gopalakrishnan V (2011) Retinoic acid induces REST degradation and neuronal differentiation by modulating the expression of SCF(beta-TRCP) in neuroblastoma cells. Cancer 117:5189-5202. CrossRef Medline

Weissman AM (2008) How much REST is enough? Cancer Cell 13:381-383. CrossRef Medline

Westbrook TF, Hu G, Ang XL, Mulligan P, Pavlova NN, Liang A, Leng Y, Maehr R, Shi Y, Harper JW, Elledge SJ (2008) SCFbeta-TRCP controls oncogenic transformation and neural differentiation through REST degradation. Nature 452:370-374. CrossRef Medline

Zuccato C, Tartari M, Crotti A, Goffredo D, Valenza M, Conti L, Cataudella T, Leavitt BR, Hayden MR, Timmusk T, Rigamonti D, Cattaneo E (2003) Huntingtin interacts with REST/NRSF to modulate the transcription of NRSE-controlled neuronal genes. Nat Genet 35:76-83. CrossRef Medline 